\title{
Observations in Malaya on Bud-rot of Coco-nuts.
}

\author{
$\mathrm{BI}$ \\ A. SHARPLES, A.R.C.S., D.I.C., \\ Mycologist, Federated Malay. States and Straits Settlement. \\ AND \\ J. LAMBOURNE, F.R.H.S., \\ Superintendent of Government Plantations, Federated Malay States.
}

\section{With Plates I-VII.}

TOHNTONE'S work on Bud-rot of Coco-nuts (4) in the West Indies was the first definite contribution towards establishing a probable cause of the disease. Coleman (3) investigated a disease of the Areca Palm (Areca Catechu), and proved that Phytophthora omnivora var. Arecae (Coleman) could attack this palm at the crown. Butler (2) about the same time worked on a Bud-rot of Palmyra Palm (Borassus flabellifera), and recorded successful inoculations of the young central heart leaves with Pythium palmivorum (Butler); recently Butler has reconsidered this fungus as Phytophthora palmivora (Butler). Johnstone (loc. cit.) forwards evidence for a bacterial origin of Bud-rot in Cocos nucifera, the causal organism being regarded as Bacillus coli (Escherlich) Migula. There would appear then to be little in common between the diseases of the three palms mentioned, except similar symptoms produced by very different causes.

Shaw : and Sundaraman (8) working on Bud-rot of Coco-nuts in Malabar performed inoculation experiments and stated that Phytophthora (Pythium) palmivora (Butler) was the cause of the disease. Their observations have received much support from the recent work of Reinking in the Philippines and Ashby in Jamaica. Ashby (1) considers Phytophthora palmivora (Butler) as the cause of Coco-nut Bud-rot in Jamaica. Reinking (7) says, 'From these researches it can be stated with certainty that Phytophthora faberi (Maubl.) causes Coco-nut Bud-rot; bacteria are apparently in the majority of cases always secondary, but are concerned with destroying the weakened tissues'. These recent investigations bring the causes of the palm Bud-rots, mentioned above, more into line; all are caused by different species of the genus Phytophthora.

No definite information, from Malaya or other rubber-growing countries of the Middle East, on the Phytophthoras causing diseases of Coco-nut

[Annals of Botany, Vol. XXXVI. No. CXLI. January, 1922.] 
palms has yet been recorded. The matter is one of some urgency as Phytophthora faberi (Maubl.) has long been known to cause a serious bark disease of Hevea brasiliensis. The absence or presence of different host plants is of primary importance when considering control measures for serious plant diseases. For this reason, following on a visit from Professor O. A. Reinking, some attention has been given to Coco-nut Bud-rot during the last twelve months, though this disease never has caused, in the writer's experience, any serious loss in Malaya.

\section{SYMPTOMS.}

The experimental results to be described are valid only in so far as an accurate knowledge of the symptoms, both early and advanced, can be obtained. For this purpose, it is necessary to go into considerable detail, drawing upon the experience of investigators in all countries where Bud-rot is a disease of importance. Johnstone (4) gives a general diagnosis of the disease as follows: 'The common name of the disease, Bud-rot, well describes its nature, for in its acute or advanced stages the bud of the tree, i. e. the growing-point in the centre of the crown, is affected by a vilesmelling soft-rot which destroys all the younger tissues. At this stage most of the nuts have fallen, the lower leaves are turning yellow, and the middle folded and undeveloped leaves are dead, and hang down between the still green surrounding leaves. Signs of the disease in its incipiency are (I) the falling of the immature nuts; (2) a staining of the opening flower spikes, partly or wholly, of a rich chocolate brown; and (3) the drying and bending over of the middle undeveloped leaves.' The same author also gives the symptoms (ibid.) as observed in different countries. On page I2: 'In many cases the descriptions (from the West Indies) are so meagre that it is impossible to identify them with the Bud-rot; nevertheless the one characteristic, the rot in the heart-tissues, is believed to apply only to this disease. In addition, the dying of the central undeveloped leaves is taken as a sign of the Bud-rot.' On page I9, under Philippine Islands, he quotes: 'As soon as the youngest leaf is noticeably discoloured it can easily be drawn out.' On page IO, under Ceylon, Petch is quoted: 'The first indication of the disease in the case of young plants is the withering of the youngest unfolding leaf. This turns brown and can be pulled out of its sheath ; it is then found to end in a soft brown mass.' On page 20, under German East Africa: 'Soon after the first appearance of the disease the heart leaves can be drawn out, as the bottom is rotted off.' Shaw and Sundaraman (8) say: 'The first symptom of which a diseased tree may be recognized is that the central leaf turns brown, collapses, and dies.' They also quote (ibid.) that Petch in Ceylon lays stress on the early withering of the central leaf in young trees, a point 
which up till then had not been mentioned by West Indian observers. Reinking (7) says: "The first symptom is a withering of the youngest unfolded leaf, followed by the leaf turning brown. Gradually the next younger leaves wither and turn brown, until the entire central group is affected. At this stage the central leaves may be easily pulled out. Frequently in advanced cases, they fall over.' Ashby (l) says: 'The existence of the disease is indicated by the pale colour, bending over, browning, and breaking down of the heart leaf.'

The quotations from the numerous investigators in both hemispheres are in agreement as to the general symptoms of Bud-rot in Coco-nuts. Investigators in the West Indies, previous to Johnstone, confused other symptoms with those of Bud-rot; the commonest symptom mistakenly associated with Bud-rot being the 'red-ring' in the stem, which has since been proved by Nowell (5) to be caused by a nematode attack. Therefore we have a definite guiding line as to the interpretation of any experimental inoculation results: "The initial browning and death of the heart leaves, which may fall over or can easily be pulled out ; if the bud-tissue is now examined it will presumably show the rot which typifies the disease.' It may be noted here that Johnstone (4) appears to be the only investigator who stresses the rotting of the central tissues. Ashby (1) also remarks that trees successfully inoculated with Phytophthora palmivora (Butler), i. e. ' showing rows of depressed spots in the central leaves', do not necessarily die at the heart.

\section{Observations in the Federated Malay States.}

Dating from the time of Professor Reinking's visit to the Federated Malay States, the senior author has been trying to obtain field information on Bud-rot of Coco-nuts, intending to prosecute an intensive investigation into the cause of the disease. A Phytophthora disease, causing falling of nuts, has been noted in Ceylon by Petch (6), but no evidence of connexion with Bud-rot is offered. It is interesting to note that Johnstone (4) mentions, as one of the incipient signs of Bud-rot, the falling of the immature nuts. This feature has been commonly met with in Malaya since 1914, but it can be categorically stated that, in this country, the falling of immature nuts has little or no connexion with Bud-rot of Coco-nuts. Ashby (1) describes a form of Bud-rot, the earliest symptom of which is usually the dropping of young nuts from one or more spikes, which blacken and wither up.

This disease has never assumed epidemic form except in one small instance, to be detailed below, in Malayan plantations. Most Coco-nut estates find a few cases, usually widely separated, at various periods of the year. Beyond cutting the diseased palms and burning them, nothing is done, and from year to year there has been no cause for uneasiness with 
regard to spread. This might be considered unusual in view of the general prevalence of 'Black Stripe' caused by Phytophthora faberi (Maubl.) on the rubber plantations of Malaya; one can only assume that the general conditions in Malaya are somewhat inimical to the well-being of this fungus, an assumption which any experienced observer in Malaya would not countenance.

During I 920 an urgent call was received from an estate in the chief Coco-nut centre in Malaya, asking for immediate advice regarding an outbreak of Bud-rot. A visit was made by the senior author, who found a three-acre field with practically every tree showing signs of Bud-rot, some in a very advanced state of decay. This field was surrounded by fields containing trees of similar age, well grown, and with no signs of Bud-rot. The badly affected field was inundated twice a day by tidal water, and the trees were very backward in consequence. There was little doubt that the primary cause of the trouble in this case was the daily inundations.

\section{Isolation and Investigation of Diseased Tissues.}

A large number of specimens in all stages of decay were taken to the laboratory from the estate mentioned above, and isolations made from the advancing margin of the diseased tissue. As the central leaves were all destroyed it was not possible to search for the depressed rows of spots described by Shaw and Sundaraman (8) and later by Ashby (1). The specimens of bud-tissue used to obtain isolations from were put up in spirit and sectioned.

One specimen (Plate I, Fig. 1) showed the rot extending below the bud to a depth of three to four inches. Isolations and sections were made from this material, and were substantially the same as the ordinary specimens. (Plate I, Figs. 2 and 3).

Examination of sections showed no obvious fungal hyphae in any of the specimens. The isolation resulted in three different organisms, one producing a deep-red pigment, the second a pale lemon-coloured growth in culture, and the third a pure-white growth.

Preliminary examination suggested all three as bacterial cultures. They were finally sent to Dr. Fletcher, Bacteriologist to the Institute of Medical Research, Kuala Lumpur, who reported as follows: 'All are non-motile. The organism producing the red pigment is a minute Grampositive bacillus'-this was taken at the commencement to be Bacillus prodigiosus.

'The organism which gives the pale lemon-coloured growth is a small Gram-positive bacillus, possibly B. flavo-coriacens (Eisenberg).

'The white growth is a minute Gram-positive fungus.' The senior author on careful examination would place this in Sarcinomyces. 
A characteristic feature in Malaya, in advanced cases of Bud-rot, is an obvious pinkish discoloration, due probably to the presence of the red bacterium in considerable quantity. This organism grows well on meatextract agar; the Sarcinomyces (?) develops well on green-pea agar; the lemon-coloured bacterium was difficult to grow, the best results being obtained on potato-mush agar.

\section{LABORATORY TESTS.}

After Professor Reinking's visit the senior author carried out various parallel tests on Coco-nut bud-tissue with the above-mentioned bacteria and Phytophthora faberi (Maubl.) isolated from 'Black Stripe' disease of rubber bark. For this purpose Coco-nut cabbage tissue was obtained and inoculated with the various organisms. These test pieces were placed under bell-jars and similar inoculated pieces were kept as controls. The results were extremely variable, as might be expected, but these tests undoubtedly showed that the bud-tissue was a highly favourable medium for all the organisms concerned. The control test pieces remained sound for several days after the inoculated ones were rotten.

The behaviour of these organisms led to the consideration of the experimental proof of the cause of Bud-rot. Obviously, the cabbage being formed of tissue containing abundant nutritive material, there would be some danger in basing conclusions on results obtained by direct wounding of the bud-tissue, no matter how small the puncture made. A fair simile would be the difference between inoculating any artificial culture medium with inoculum from a culture, and inserting a sterile needle in a tube of the same medium. Analysing Reinking's (7) latest results on this basis we find :

Young trees. (I) Stab in damp chambers

(2) Stab outside in shade

" (3) Uninjured in shade

Old trees. (4) Stab (three mature trees outside, one not examined)

\begin{tabular}{rrrr}
\multicolumn{2}{r}{ Inoculated. } & \multicolumn{2}{c}{ Controls. } \\
+ & - & + & - \\
3 & 2 & 0 & 0 \\
$\mathrm{I} 4$ & $\mathrm{I}$ & 0 & 7 \\
2 & 6 & 0 & 2 \\
$\mathrm{I}$ & 0 & $\mathrm{I}$ & 0
\end{tabular}

These results were obtained by using Phytophthora faberi isolated from Cacao pod-rot. Later he isolated Phytophthora faberi from the woody tissue below the growing-point of a Coco-nut palm showing Bud-rot. With this fungus thirteen inoculations were made in seedling Coco-nuts by stabsall were successful. Only two controls were kept which remained healthy.

On the above reasoning and analysis the present writers were of the opinion that more work was necessary before accepting Reinking's conclusion in toto, i. e. 'From these researches it can be stated with certainty that Phytophthora faberi (Maubl.) causes Coco-nut Bud-rot; bacteria are 
apparently in the majority of cases always secondary, but are concerned with destroying the weakened tissues'.

Again, the writers are convinced that too much importance is attached to results of inoculation on seedlings in the laboratory. No disease on mature trees can be considered finally proved until the typical symptoms have been reproduced by artificial inoculations on mature trees. Valuable information as to the possible cause of the disease on mature trees may be obtained by experimental inoculations on seedlings, but more often than not this is put forward and is often accepted as proof conclusive. That such is not always the case the following series of experimental inoculations will show very clearly.

As we were not attempting to prove a specific cause of Bud-rot no attempt was made to identify the cultures worked with specifically. It will be convenient for our purpose to tabulate results under group letters, the following key giving the necessary information to the organism used for inoculating the trees:

$$
\begin{aligned}
\text { Organism } A & =\text { Phytophthora faberi (Maubl.). } \\
, \quad B & =\text { Red-pigmented bacillus. } \\
, \quad & C=\text { Sarcimonyces sp. } \\
, \quad D & =\text { Mixture of } B \text { and } C .
\end{aligned}
$$

The inoculations were made by clearing away the leaves and leaf bases on one side of the tree. A suitable point for inserting a small gouge was chosen and cleaned externally with spirit; the instrument was flamed before boring into the heart. When the tender central tissues are reached there is usually some exudation of water; if the gouge is now withdrawn carefully the tissue from the bore-hole will come out lying in the concave side of the gouge. This tissue was inoculated with the various organisms and pushed back into the bore-hole with the handle of a flamed needle-holder.

The tabulated results show that in the Group $A$ inoculations only one tree, No. 4, remained healthy up to 8.3.21. Tree No. 7, badly attacked on 8.10.20 and 9.II.20, is fully recovered on 8.3.2I. Trees Nos. 8, 9, and 10, attacked at various stages, show no definite signs on 8.3.2 I, but on this date eight trees still show signs of attack in various stages.

Of the six control trees for Group $A$, two were attacked by beetles, which somewhat upsets the value of the control. However, three trees appeared to have a bad attack on 8.10.20, but on 8.3.2I only one tree out of five (one was cut out for examination) showed signs of attack.

The trees in Group $B$ on 8.10.20 showed a rapid and very definite attack, seven trees out of eight being very severely attacked. At this date, if the red-pigmented bacillus had been the only organism worked with, we might have concluded that this was the probable cause of the disease in Malaya. All the central shoots were black and decayed, most of them 


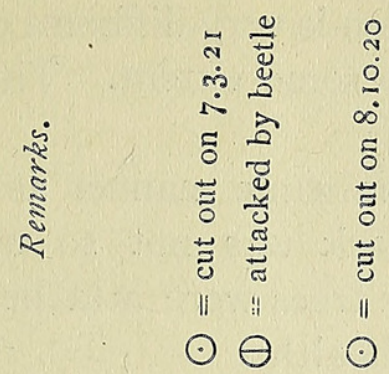

$\oplus \oplus \triangleleft$

(1) $\oplus \triangleleft$

$\triangleleft \oplus \triangleleft$

(1) $\triangleleft$

$\triangleleft \triangleleft \oplus$

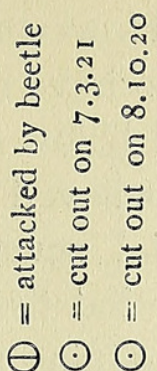

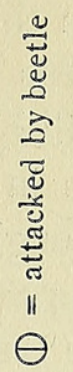

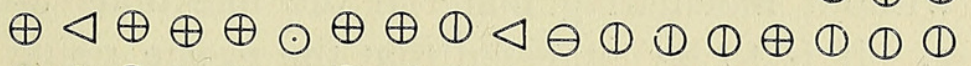

$\oplus \oplus \oplus \mathbb{1} . \mathbb{( 1 )} \oplus \triangleleft \oplus \oplus \oplus \mathbb{1} \oplus \triangleleft \triangleleft \oplus \oplus \oplus \mathbb{1}$

(1) (1) $(1 \oplus \oplus \mathbb{1} \oplus \oplus \mathbb{D} \oplus \oplus \Phi \Phi \oplus \triangleleft \oplus H \oplus$

(1) $(1) \oplus \ominus \ominus \oplus \oplus \oplus \mathbb{1} \oplus \oplus \oplus \Phi \oplus \triangleleft \oplus H \oplus$

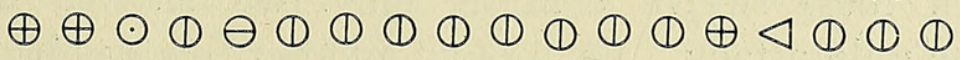

(1) $\oplus \oplus \oplus \oplus \triangleleft \triangleleft \oplus \oplus \oplus \triangleleft \oplus \odot \odot \odot \odot \oplus$ (1) (1)

东

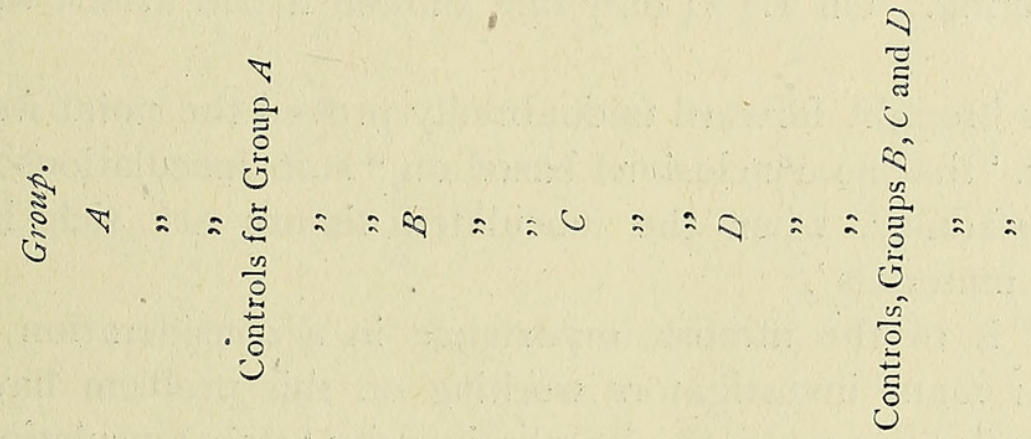

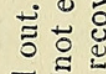

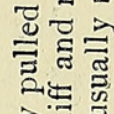

$\therefore \div$

可

के $\overline{\mathrm{s}}$

品

ङ

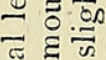

घี สँ

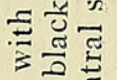

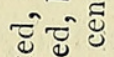

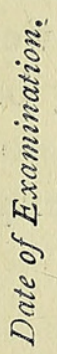

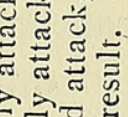

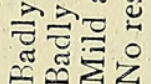

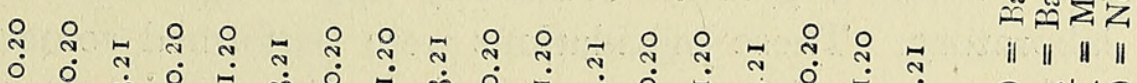

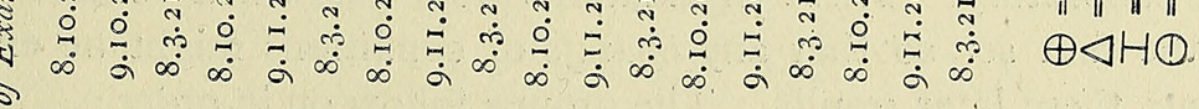

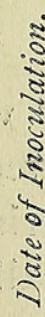

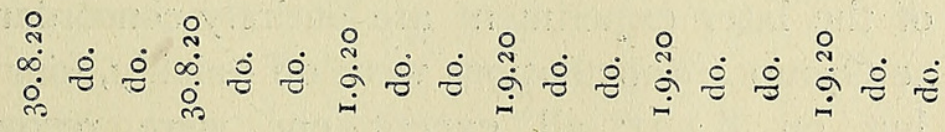


falling over on their own. However, the position is very different on 8.3.2 I, when these trees appeared to have recovered to some extent. The manner of recovery will be discussed below.

The trees in Group $C$ behaved in much the same manner as those in Group $B$, though the initial severity of attack was not so noticeable. During the experimental period five out of six trees were attacked, but on 8.3.2 I the five trees still remaining were quite healthy.

Group $D$, inoculated with a mixture of $B$ and $C$, shows a different course of events, the attack being slowed up considerably. On 8.3.2I, of the five trees remaining, all showed evidence of attack. This result is probably connected with the initial hold-up; it is to be expected that all these trees will recover.

The twelve controls established for the bacterial infections show definitely that without inoculating material the infections are neither so rapid nor severe. It is to be expected that the gouge going through the leaf-bases will, in some cases, carry material into the centre which, on reaching the nutritive bud-tissue, will ultimately develop and possibly cause a Bud-rot. In these twelve controls only two showed definitely on 8.10.20, with one mild attack. On 9.II.20 another tree was badly attacked, and another very mildly attacked, and one of the previous badly attacked trees was recovering. On 8.3.2 I only one showed a bad attack with three mild attacks.

The results brought forward undoubtedly proved the point we set out to establish, i. e. "that no conclusions based on "stab inoculations" can be considered satisfactory, when the inoculated tissues are rich in easily converted food materials'.

This point is of the utmost importance in a consideration of Budrot of palms, for many investigators working on this problem have based their conclusions largely upon results obtained by 'stab inoculations'. In order to establish the point more firmly, further inoculations were made with three different organisms commonly appearing on rotting bud-tissue in the laboratory. These inoculations were performed some two months after the first set, so that any change of conditions might be expected to influence these later results. The groups follow on in order:

Group $E$ inoculated with Thielavia sp.

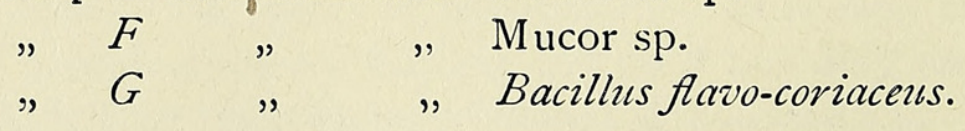

The results of the later experiment are entirely concordant with the previous one. The Group $E$ inoculations went off quickly, four trees being badly attacked, but on 8.3.2I all except one were recovering-one remained healthy throughout. The sequence of events parallels the Group $B$ inoculations. The Group $E$ inoculations started very slowly 


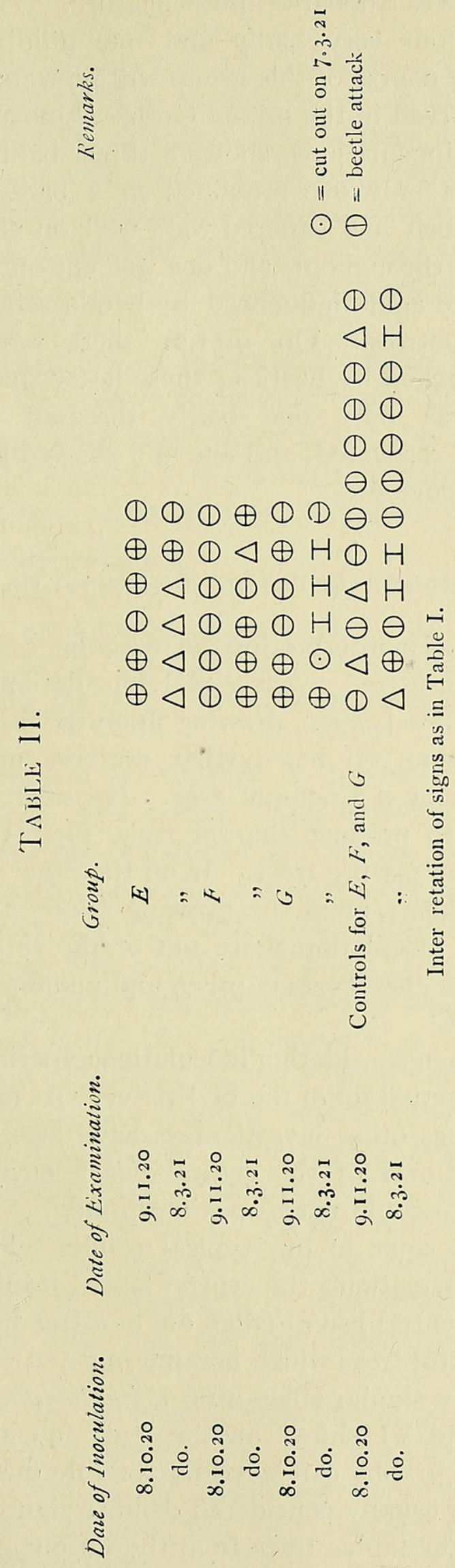


and on 9.II.20 the trees appeared quite healthy. The second inspection on 8.3.2I revealed four very badly and one mildly attacked and one healthy. The further course of this group will be watched. The sequence is similar to that observed in the mixed Group $D$ inoculations.

The Group $G$ inoculations showed three badly infected cases on 9.II.20, but on 8.3.2 I only one remained in a badly diseased condition, while three others which had suffered were well on the road to recovery; only one was healthy throughout, and one was cut out for examination.

The controls were again influenced by beetle attack, noted previously in the Group $A$ controls. On 9.II.20 there were only three mild attacks and three attacked by beetles; these latter were otherwise healthy. On 8.3.2I there was only one badly diseased tree, three slightly attacked were almost recovered, and one still showed a mild attack with no obvious attempt at recovery.

\section{INTERPRETATION OF RESULTS.}

The essential point in interpreting the foregoing results is the recognition of what is to be considered a successful inoculation. The writers have stated their guiding line (supra), drawing upon the experience of previous investigators. Johnstone (4) has further remarks upon the difficulty of inoculating the heart of a Coco-nut tree. He says, 'Inoculations made below the heart fail to produce the rot, since these tissues naturally soon harden as a part of the mature trees. If, on the other hand, the inoculation be made above the heart, amid the growing leaves, their extremely rapid elongation takes the inoculation point out of the surrounding soft tissues. The inoculated tissues then become green and membranous, and thus resist the advance of the rot.'

Johnstone (4), when considering inoculation experiments, rightly stresses the necessity for the actual rot of the bud-tissue. As far as our acquaintance with the literature goes other investigators have been satisfied to produce a rotting and falling over of the central heart leaves-in such case our inoculations marked $\oplus$ could not be misinterpreted.

The plates show some of our typical results. Plate II shows a tree from the Group $G$ inoculations, the central leaves leaning and about to fall. Plate III shows the central leaves fallen out of a tree in Group $C$. Plate IV shows one of the control trees which became infected with the centre falling out. Plate $\mathrm{V}$ shows a similar effect after a Phytophthora faberi inoculation (Group $A$ ), and Plate VI shows another tree inoculated with the same fungus. These photographs can leave no possible doubt as to our success in obtaining what are usually considered definite signs of Bud-rot.

As indicated in the tables, trees from the various groups were taken out at intervals to note the progress of the inoculations. On 8.10.20 two trees 
from which the central shoots had fallen out were cut down and examined : these were No. I in Group $D$, and No. 6 in the controls for Group $A$. The first showed a mixed crowd of putrefying organisms on the top of the bud-tissues and investing this externally for $I \frac{1}{8}$ in. all round, the pink colour, probably due to the red-pigmented bacillus, predominating. When the heart-tissue was cut open there was no penetration to be observed: the cabbage appeared quite sound internally. The second tree (Group $A$ control) showed the bud invested similarly, but, on cutting open the hearttissue, penetration to a depth of 2 in. internally was found. This was undoubtedly Bud-rot.

The observations made on these two trees led to the conclusion that in most cases where the central leaves were badly diseased, a rotting of the bud would follow, and, as comparatively few of the controls showed a bad attack, the writers felt justified in assuming at the time that the introduced organisms, placed directly in the bud, were capable of causing, in the field, a typical Bud-rot on mature trees.

The attacked trees were left to develop, but, as time passed, it became obvious that events were pursuing a course contrary to that anticipated. This was most obvious in Group $B$; four of these had their central shoot pulled out quite easily, the others were left untouched. On 8.3.2I, however, all had recovered.

The general method of recovery is distinctly peculiar. Plate VII, Fig. I, shows the type. The central shoot has disappeared, but from the side of the bud below the remains of the central shoot a lateral shoot is pushed out. The leaves comprising this lateral shoot are strangely aborted, the leaflets being very stiff and only partially developed. Growth of this lateral shoot continues, and it takes the place of the central shoot. The leaves open out and present the appearance shown in Plate VII, Fig. 2, which is a photograph of tree No. I in Group $C$.

This tree was cut out on $7.3 .2 \mathrm{I}$, and a close examination of the central leaves and bud-tissue made. Another central shoot was coming up, and on examination this showed the same aborted leaves inside the central sheath. The bud was healthy, as were the lower $18 \mathrm{in}$. of the new central shoot. Above the lower 18 in., for 12 in. or so, undoubted evidence of a diseased condition was observed-a black, slimy bacterial appearance being quite marked. A photograph of this peculiar state of affairs was a failure. Another tree was cut out which showed just the same condition.

On 7.3.21 tree No. 2 of the Phytophthora faberi group was cut out for examination. Before cutting, this tree had only the external leaves standing (Plate VII, Fig. 3), the bud-tissue being absolutely rotted (Plate VII, Fig. 4). This has been the only definite case of Bud-rot noted throughout all our inoculations. 


\section{CONCLUSIONS DRAWN FROM WORK RECORDED ABOVE.}

It can be taken as definitely established:

I. That if the nutritive bud-tissue of Coco-nuts is a suitable pabulum for any saprophytic organism, either bacterium or fungus, this will develop and cause symptoms usually associated with Bud-rot if inoculated directly into the bud-tissues.

2. Owing to a very definite resistance exercised by the bud-tissues of mature trees against infection, such organisms in the absence of suitable conditions will not develop beyond a certain stage, marked by the death of the central shoot. If the central shoot dies, and the bud is invested externally with the invading organism, the bud-tissues have the power of pushing out a lateral, by means of which growth is continued to take the place of the diseased central shoot.

\section{Bearing of above on previous Bud-rot investigations.}

The above conclusions exercise considerable influence on previous recorded work. The prevailing idea that growth is no longer possible if the central shoot is killed must now be considered a fallacy, though it must be admitted that healthy growth is not immediate even if lateral shoots are produced. There is no doubt, however, that the trees producing the aborted central shoots do finally recover and put out healthy ones.

The proved resistance of mature trees negatives conclusions based on seedling inoculations, more especially when these inoculations have been aided by artificial humidity conditions as in damp chambers. Short-time observations in recording results of inoculation experiments on mature trees must also, in the light of our experiments, be of minor importance when the question of experimental proof of Bud-rot is considered.

Whilst concerned primarily with Reinking's work (7), it will be advisable to consider the work of other authors in view of the recorded facts. Coleman (3), in his work on the Areca Palm, showed his Phytophthora omnivora var. Arecae to be primarily concerned in causing a nut disease, but he records one inoculation made in the top of the tree with a suspension of zoospores, which, two weeks after inoculation, showed the fungus grown through the underlying leaf-sheaths and attacking the growing-point. He concludes from this that a direct infection of the tree-top (presumably budtissue) by means of zoospores is possible, a perfectly admissible conclusion even from one observation only.

Butler (2), in his work on Palmyra Palm Bud-rot, got undoubted parasitic penetration of the leaf sheaths with Pythium (Phytophthora) palmivorum (Butler), but twenty-eight days was the longest time allowed between inoculation and examination. No rotting of the bud was observed in any single case.

Johnstone (4) in his work, records his inoculations, and worked more 
along the lines of the present writers, by trying to induce rotting of the bud-tissues on mature trees by artificial stab inoculations. His conclusions are based on results in which the time period allowed between inoculation and examination was generally from eight to sixteen days. He also records two other inoculations: one performed on June 22, with a bacterial culture, showed a Bud-rot on October $2 \mathrm{I}$; the second, similarly treated on July 22, showed no evidence of Bud-rot on August 6. As stated, too much importance cannot be attached to results and conclusions when the period elapsing between inoculation and examination is so short, for it is obvious from the inoculations recorded above that, êven if organisms are introduced directly into the bud-tissues, their behaviour may be very different. The Group $D$ and Group $F$ inoculations were significant in this respect, for the period elapsing between inoculation and the first signs of diseased tissues was well over two months, whereas in all the other groups the first signs were almost immediate.

Shaw and Sundaraman (8), working with Butler's Pythium (Phytophthora)palmivorum, when considering Bud-rot of Coco-nuts, obtained results similar to those of Butler in his work on Palmyra Palm Bud-rot. They obtained depressed spots without wounding on the tender central leaves, indicating a parasitic penetration by the fungus. They also obtained collapse of the central shoot in a seedling Coco-nut when inoculated and kept in a damp chamber.

Their inoculation experiments were wholly upon seedlings, no mature palms being utilized. The only admissible conclusion here as in the previous work of Butler, is that inoculations with Phytophthora palmivora (Butler) result in a decided parasitic penetration of the central leaves, without any necessary connexion with rotting of the 'Bud'.

Reinking's work has already been considered. In view of the fact that his inoculations were practically all stab inoculation on seedling Coco-nuts, the evidence brought forward for Phytophthora faberi as the cause of Bud-rot in the Philippines cannot be considered satisfactory, and no definite conclusion as to the cause of Bud-rot can be arrived at. As regards our Phytophthora faberi (Maubl.) inoculations, they were no better or worse than inoculations made with the other recorded organisms. Most are recovering, and, although the only genuine Bud-rot occurred in this group, a successful inoculation on one tree is not sufficient to base important conclusions upon, when the remainder behave as other groups inoculated by widely different organisms.

Ashby's work ( 1 ) is of interest as confirming Butler's (2) and Shaw and Sundaraman's work (8). He records similar features, and from his observations fairly concludes that inoculated trees showing rows of typical Phytophthora palmivora spots on central leaves do not necessarily die at the heart. 


\section{CONCLUSTONS.}

The general impression obtained from the results of the workers cited is that all the Bud-rot diseases of Eastern and Western Hemispheres are attributable to one or more species of Phytophthora, but, judging from our experiments, it would appear that what has been proved is that Phytophthora palmivora (Butler) functions as an obligate parasite on the tender central leaves of most palms, but has not been proved to cause rotting of the 'heart-tissues'. This obligate parasitism has been very definitely demonstrated in India by Butler (2) and Shaw and Sundaraman (8), and lately by Ashby (1) in the West Indies. However, this cannot be regarded as any proof of the cause of the rotting of the bud-tissues, no more than the death and falling of the central leaves in our experiments can be considered as proving the rotting of the central bud. In these latter cases, if the bud was rotted, then the conception that the slightest invasion of the heart-tissues by a parasitic organism will result in death must go by the board.

The question then arises, 'What is Bud-rot?' The conception of Bud-rot causing death of the tree must be strictly limited to the rotting of the heart-tissues; a diseased condition of the central leaves does not necessarily connote the death of the tree.

Our conclusions are well stated in a review signed ' $W . \mathrm{N}$.' in the 'West Indian Agricultural News'. ${ }^{1}$ The writer reviews Reinking's recent work (7), and says: 'Notices of Mr. Reinking's paper have already appeared in the Journal of the Agricultural Society of Trinidad and of the Board of Agriculture in British Guiana, and the announcement has naturally aroused the greatest interest, from its possible bearing on the Bud-rot problems in the West Indies.

'The present reviewer, when recently in Trinidad, found a tendency on the part of Coco-nut planters to assume that the results obtained in the Philippines were immediately applicable to the local affection, while the British Guiana Journal in an editorial comment states: "There is little doubt that a careful scientific investigation here will prove a similar relationship between Phytophthora faberi and Bud-rot."

"Assumptions of this kind are to be deprecated, and there are special reasons for caution in the case of Bud-rot. The writer (W. N.) has insisted from time to time on recognition of the fact that the existence of Bud-rot in coconut palms is not of itself evidence of the presence of a specific disease, or of disease at all, in the ordinary sense of the word. Bud-rot is a condition which may be induced by mechanical and chemical or parasitic interference with the life processes of the palm. The material of the heart is extremely tender, and when the natural resistance ${ }^{2}$ of the living tissue

1 Vol. xviii, No. 46 I, December 27 , I919.

2 Possibly greater than is usually thought. - A. S. and J. L. 
is reduced, it forms a highly nutritive medium suitable for the rapid development of any of a large variety of possi s e invading organisms. In the case of epidemic or infective Bud-rot, the issue is narrowed down to the responsibility of a transferable parasite; but there is no ground for assuming that the parasite concerned in producing a condition of such a general nature is necessarily or even probably the same in different situations. J. R. Johnstone, now confirmed to some extent by Reinking, has put forward evidence to show that Bacillus coli may be effective in setting up Coco-nut Bud-rot. The widely prevalent and destructive Bud-rot of palms in Southern India has long been known to be due to Phytophthora palmivora (Pythium palmivorum), and the same fungus has recently been found by S. F. Ashby in connexion with Coco-nut Bud-rot in Jamaica.'

This statement from the West Indies is of considerable importance in view of the facts put forward in this paper. The views of the present writers are faithfully stated in the above quotation, although not agreeing that Bud-rot of palms in India has been proved to be due to anything. However, Phytophthora palmivora (Butler) undoubtedly has been proved to be an obligate parasite on Palmyra Palm in India, and on Coco-nut Palm in both the West Indies and India. Under suitable conditions for growth and spread we might be justified in assuming that this fungus would be the deciding factor in any epidemic, though this must be proved by inoculations on mature trees before final conclusions can be stated.

We must express our deep indebtedness to Dr. Fletcher, Bacteriologist to the Medical Research Institute, for his kindness in examining the bacterial cultures used by us in our inoculation experiments.

\section{REFERENCES.}

1. Ashby, F. S. : Notes on two Diseases of Coco-nut Palm in Jamaica caused by Fungi of the Genus Phytophthora. West Indian Bulletin, vol. xviii, Nos. 1 and 2, 1920.

2. Butler, J. E. : Some Diseases of Palm. Agricultural Journal of India, vol. i, pt. 4, October 6, I 906, and Memoirs of the Department of Agriculture of India, vol. i, No. 5, February, 1907.

3. Coleman, C. Leslie: Diseases of the Areca Palm. Annales Mycologici, igro.

4. Johnstone, R. John: The History and Cause of the Coco-nut Bud-rot. Bureau of Plant Industry, United States Department of Agriculture, No. 228.

5. Nowell, W.: The Red-ring Disease of Coco-nut Palms. West Indian Bulletin, vol. xvii, No. 4.

6. Pетch, T.: Nut Fall and Leaf Droop of Coco-nuts. Leaflet No. 6, Department of Agriculture, Ceylon, and (same title) Tropical Agriculturist, vol. xlix, No. 6, Dec., I9I7.

7. Reinking, A. Otto: Coco-nut Bud-rot in the Philippines. Philippine Journal of Science, vol. xiv, No. I, January, I919.

8. Shaw, F. J. F., and Sundaraman, S.: The Bud-rot of Coco-nut Palms in Malabar. Annales Mycologici, vol. xii, No. 3, I9I 4, and Agricultural Journal of India, vol. ix, pt. 2, I 9 I 4. 


\section{EXPLANATION OF PLATES I-VII.}

Illustrating Mr. Sharples' and Mr. Lambourne's paper on Observations in Malaya on Bud-rot of Coco-nuts.

\section{PLATE I.}

Fig. I. Section of fibrous tissue below bud, showing extension of rot into tissues below the bud. Figs. 2 and 3. Typical appearance of heart-tissues in advanced cases of Bud-rot.

\section{PLATE II.}

Inoculated tree in Group $G$ (Bacillus flavo-coriaceus); central leaves leaning before falling.

\section{PLATE III.}

Inoculated tree in Group $C$ (Sarcinomyces); central leaves fallen.

\section{PLATE IV.}

Control tree in Phytophthora controls; central leaves fallen.

\section{PLATE V.}

Jnoculated tree in Group $A$ (Phytophthora faberi); central leaves fallen.

\section{PLATE VI.}

Inoculated tree in Group $A$; central leaves about to fall.

\section{PLATE VII.}

Fig. I. Showing typical appearance of tree recovering after losing central leaves. The outer leaves have been cut away to show the early stage of the new shoot pushed out laterally.

Fig. 2. Shows appearance of aborted central leaves after recovering.

Fig. 3. Successful Bud-rot inoculation with Phytophthora faberi (Group A). Only external leaves left standing.

Fig. 4. Central tissues of above tree, showing diseased condition. 

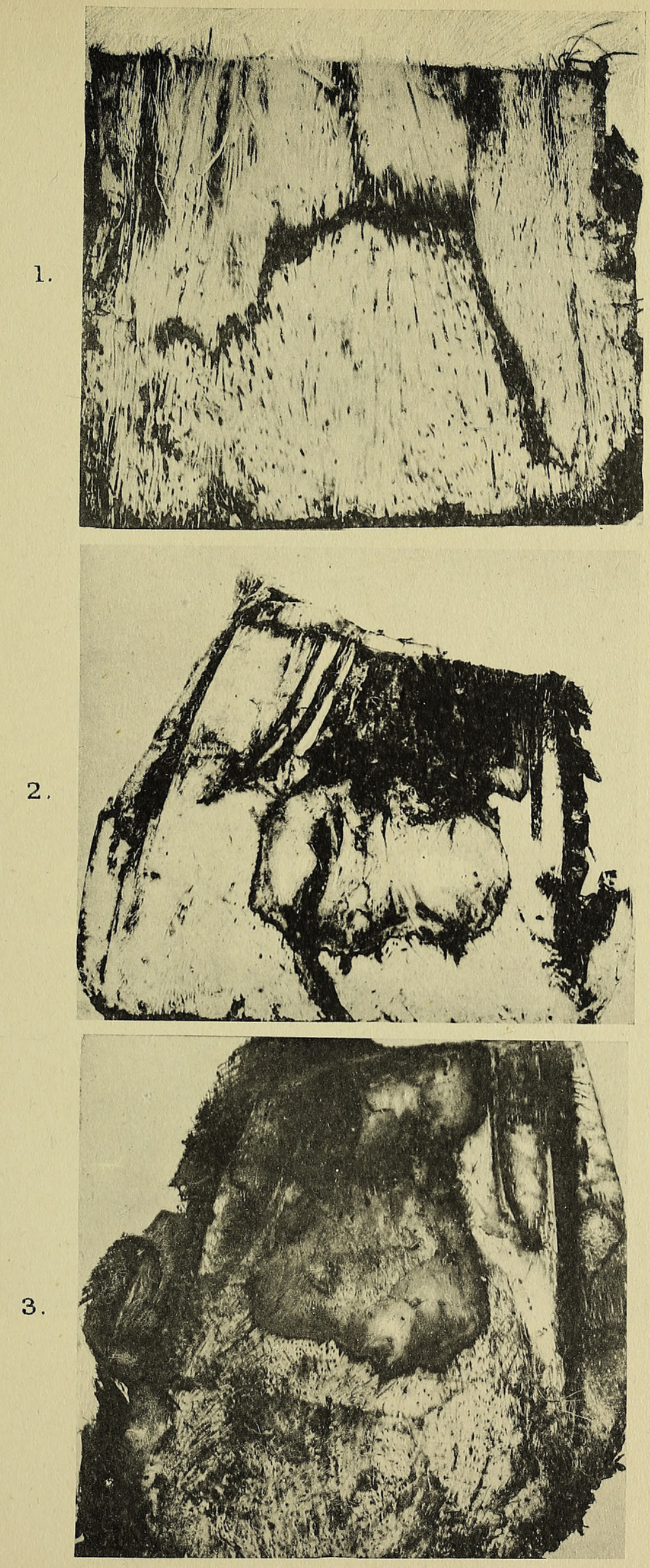


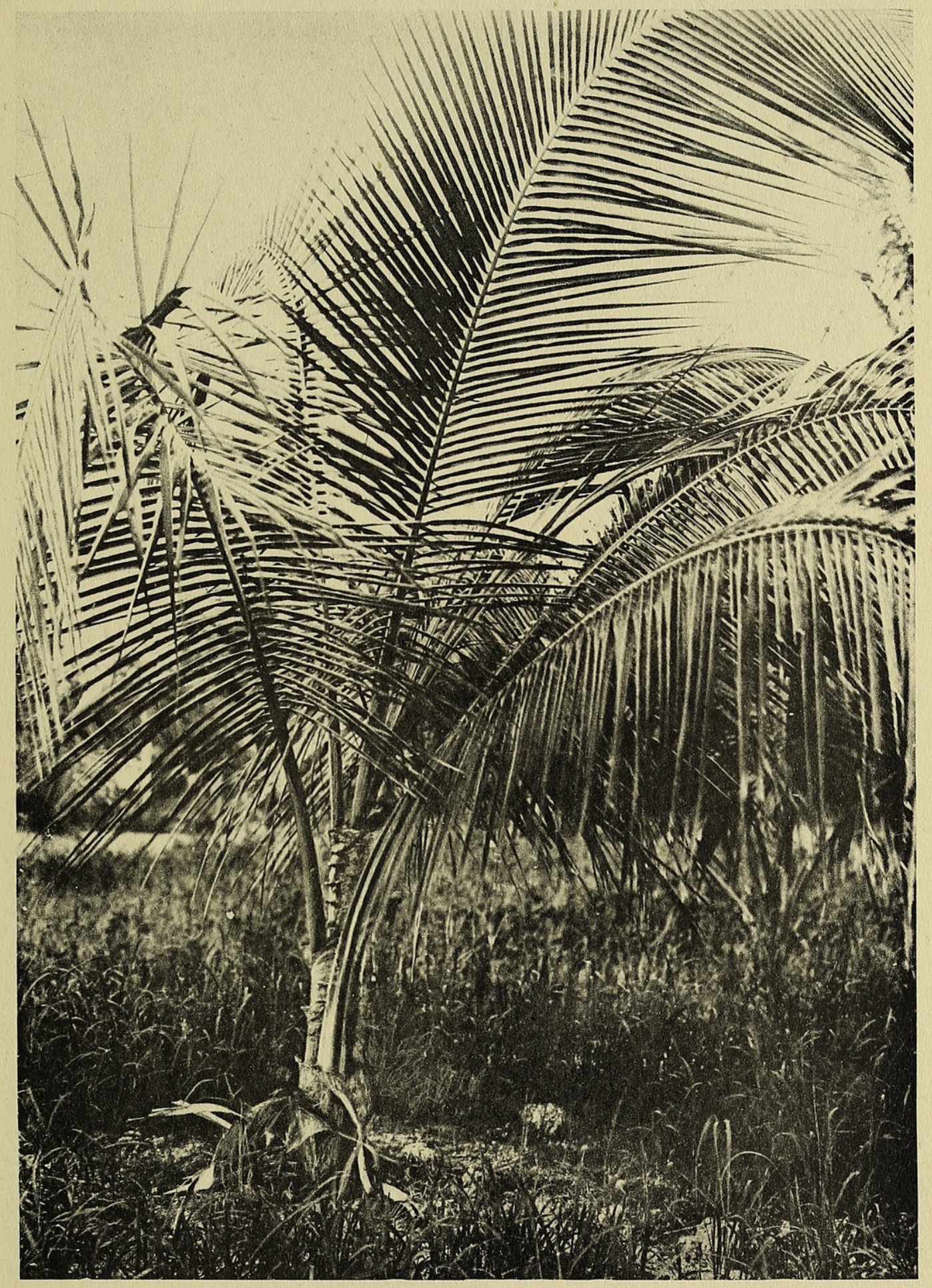

SHARPLES \& LAMBOURNE-BUD ROT. 


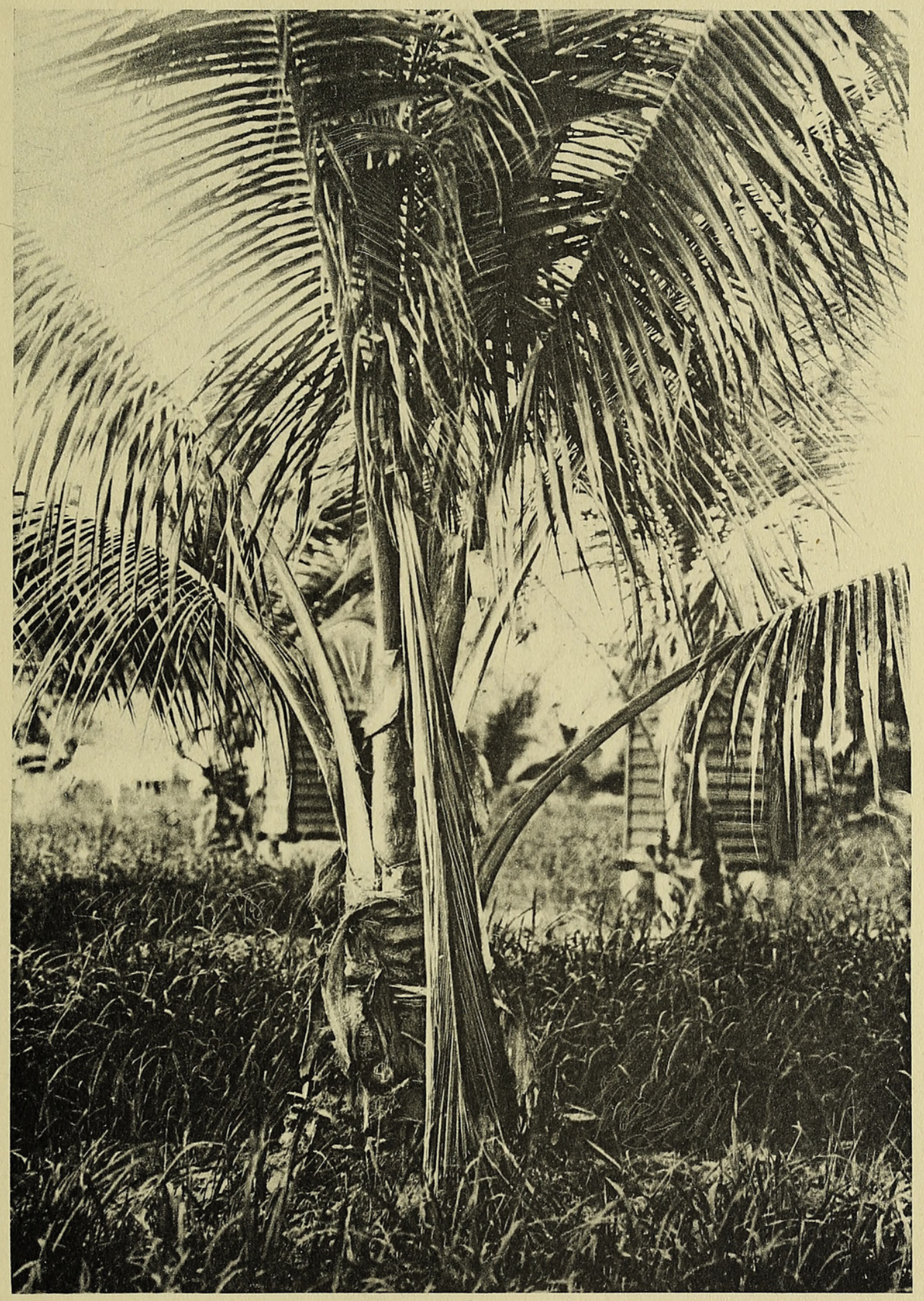

SHARPLES \& LAMBOURNE - BUD ROT. 


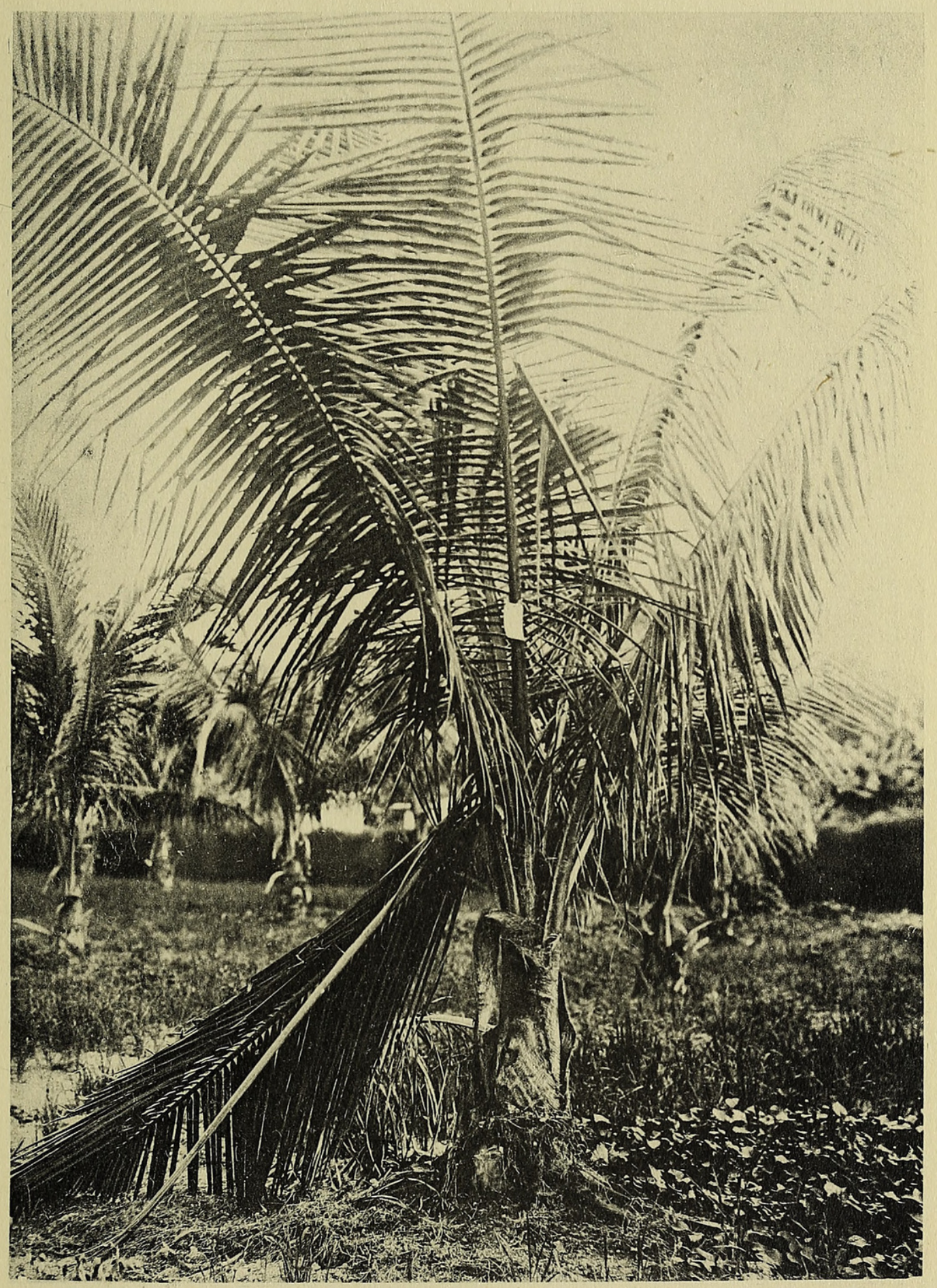

SHARPLES \& LAMBOURNE - BUD ROT. 


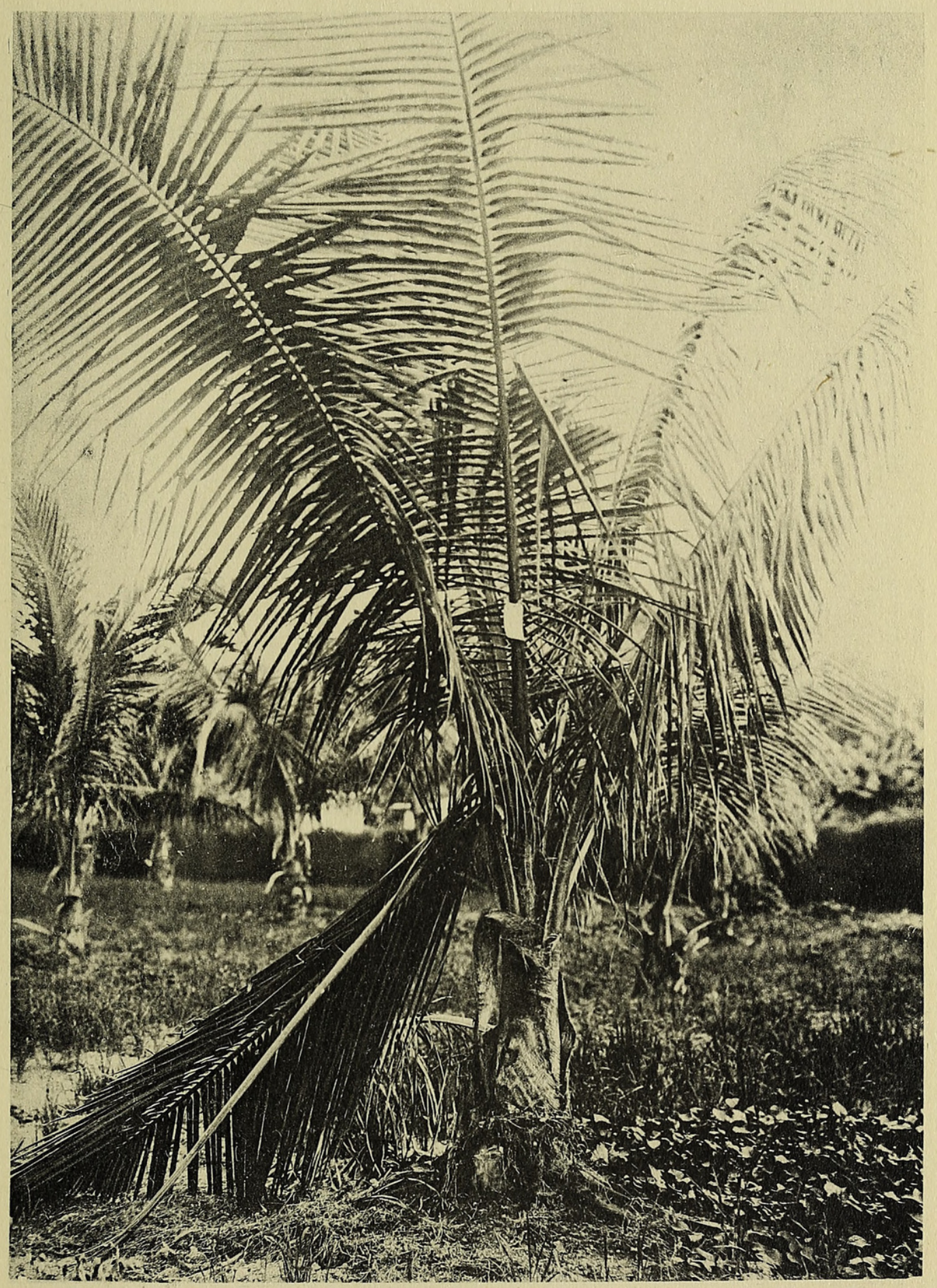

SHARPLES \& LAMBOURNE - BUD ROT. 


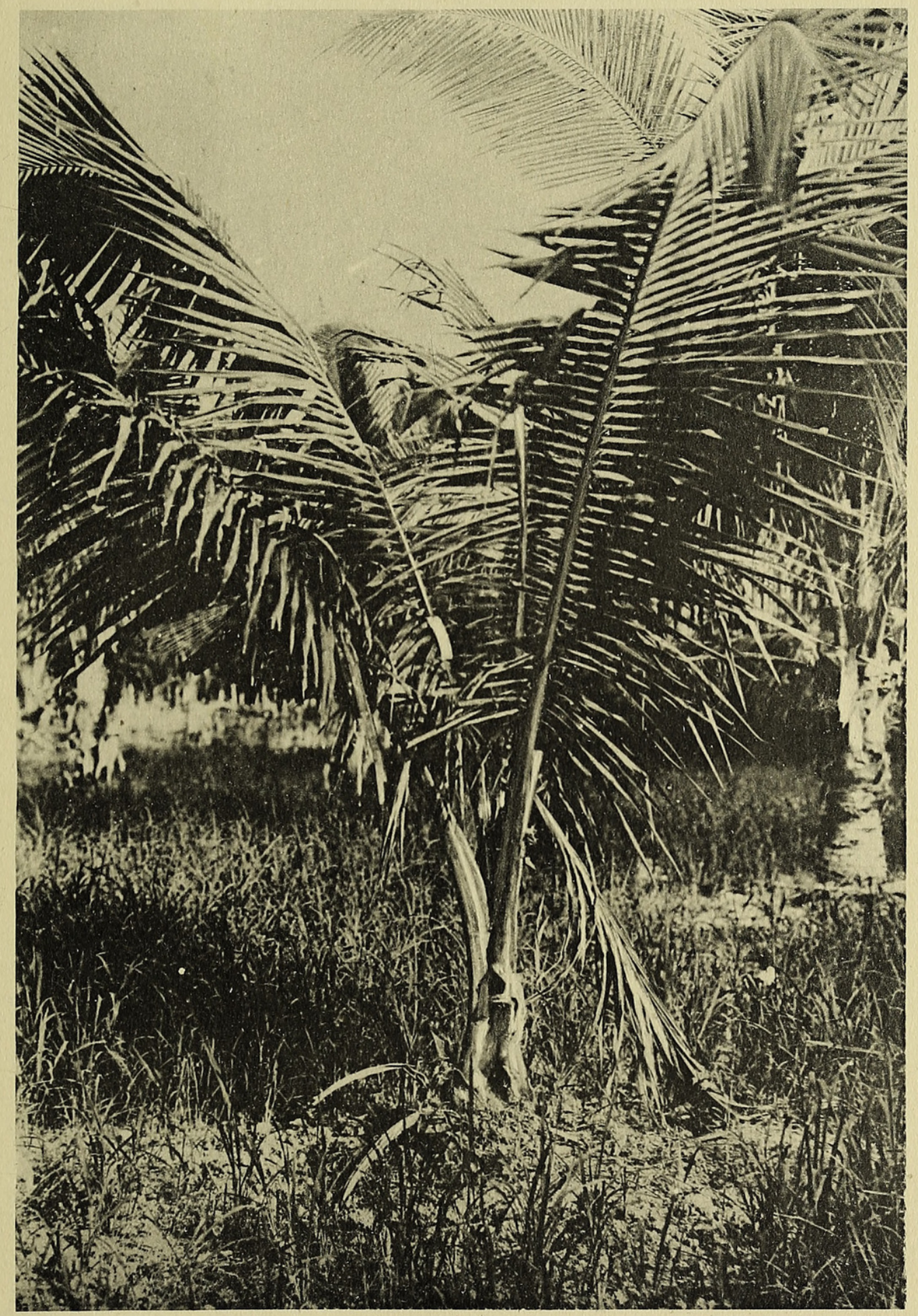

SHARPLES \& LAMBOURNE - BUD ROT. 


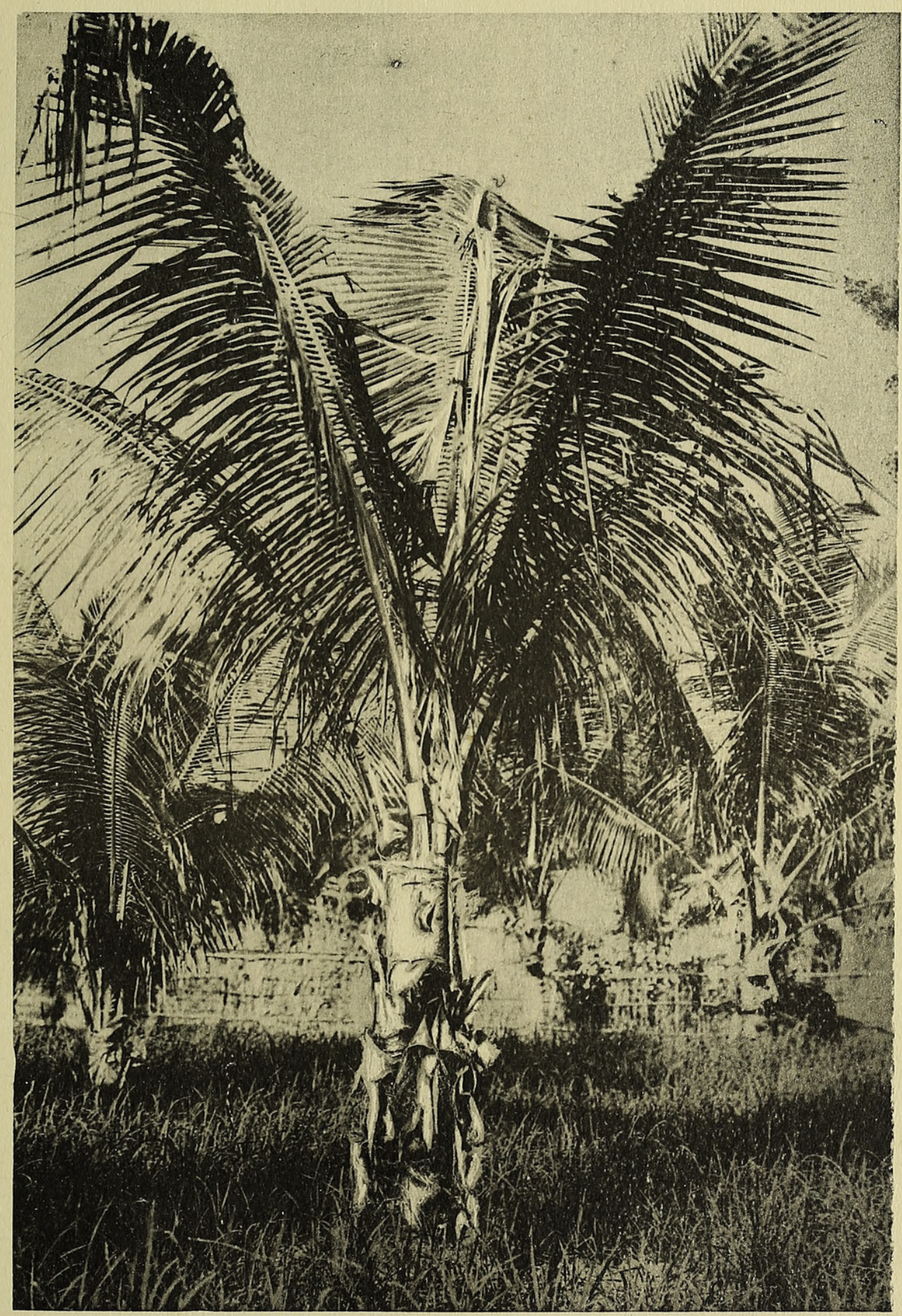

SHARPLES \& LAMBOURNE - BUD ROT. 


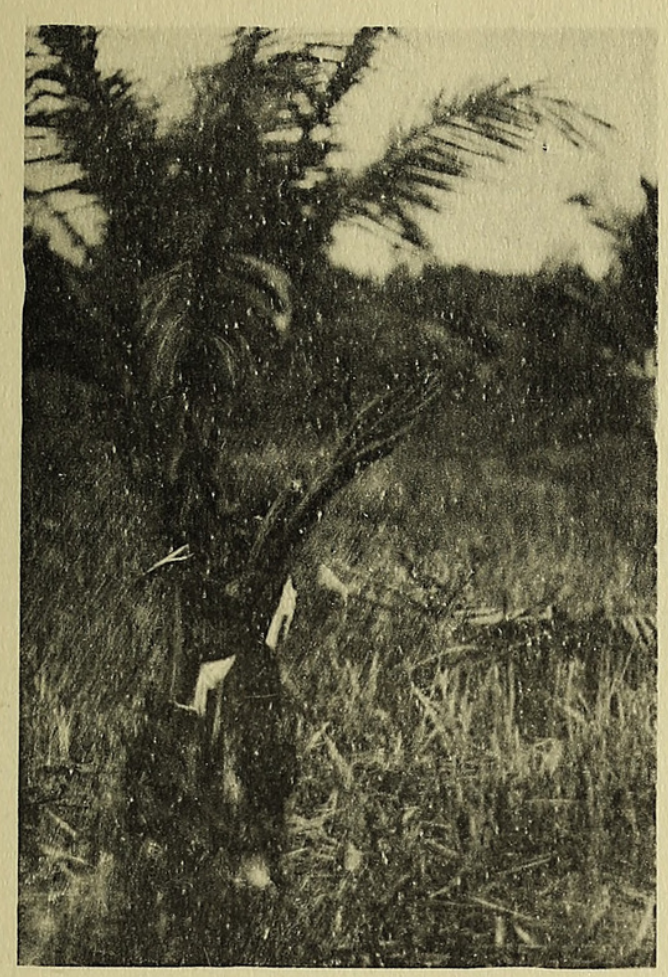

1.

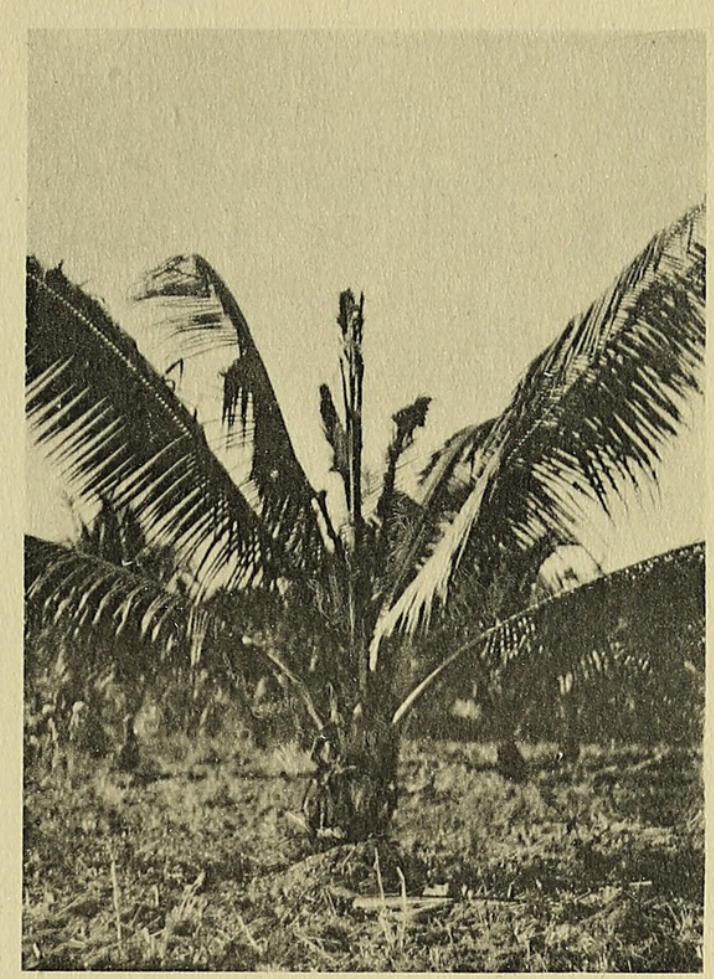

2.

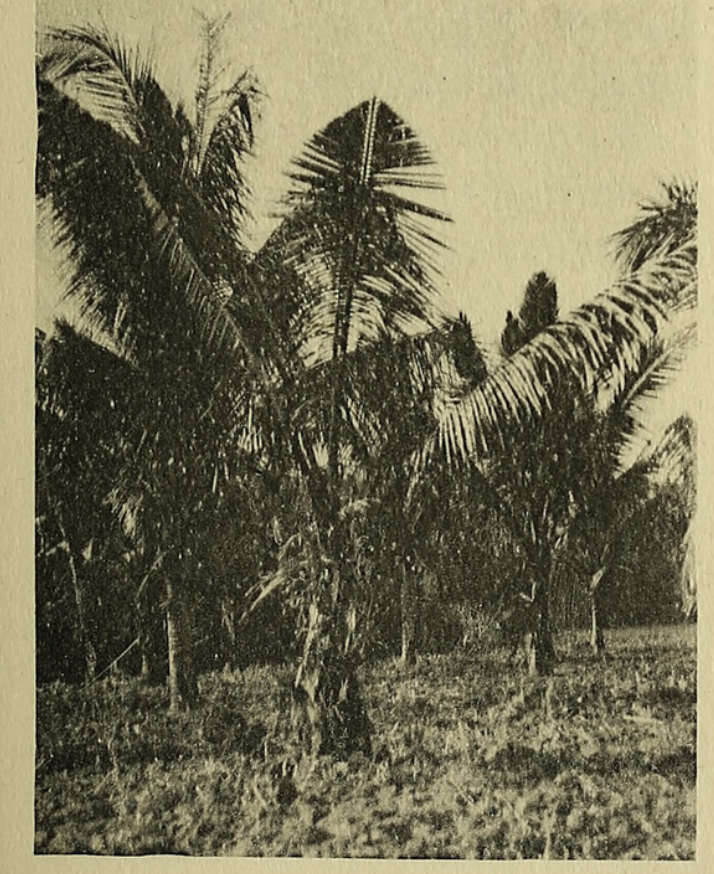

3.

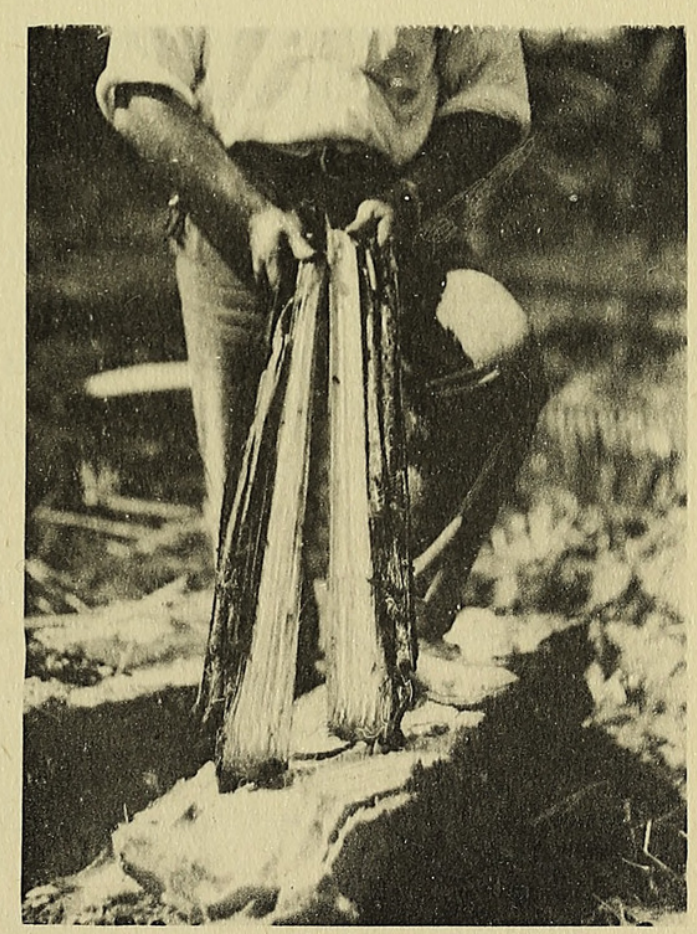

4.

SHARPLES \& LAMBOURNE - BUD ROT. 


\section{$2 \mathrm{BHL}$ Biodiversity Heritage Library}

Sharples, A. and Lambourne, J. 1922. "Observations in Malaya on bud-rot of coco-nuts." Annals of botany 36, 55-70.

https://doi.org/10.1093/oxfordjournals.aob.a089787.

View This Item Online: https://www.biodiversitylibrary.org/item/234428

DOI: https://doi.org/10.1093/oxfordjournals.aob.a089787

Permalink: https://www.biodiversitylibrary.org/partpdf/319027

\section{Holding Institution}

Smithsonian Libraries

\section{Sponsored by}

Biodiversity Heritage Library

\section{Copyright \& Reuse}

Copyright Status: Not in copyright. The BHL knows of no copyright restrictions on this item.

This document was created from content at the Biodiversity Heritage Library, the world's largest open access digital library for biodiversity literature and archives. Visit BHL at https://www.biodiversitylibrary.org. 